\title{
The maintenance of motility and the surface properties of epididymal spermatozoa from bull, rabbit and ram in homologous seminal and epididymal plasma
}

\author{
H. M. Dott, R. A. P. Harrison and G. C. A. Foster \\ A.R.C. Institute of Animal Physiology, Animal Research Station, 307 Huntingdon Road, \\ Cambridge CB3 OJQ, U.K.
}

Summary. Epididymal spermatozoa from bull, rabbit and ram were incubated in homologous epididymal plasma or seminal plasma in a buffered saline-based medium with or without serum albumin. The spermatozoa were either diluted directly into the medium or were washed first.

No effect of washing was observed on the subsequent reaction of the cells to the different media.

A considerable proportion of the populations of epididymal spermatozoa survived (i.e. continued to exhibit motility) for up to $22 \mathrm{~h}$ at $30^{\circ} \mathrm{C}$ in the simple saline-based medium. Initially epididymal plasma had a slight stimulatory effect on sperm motility in ram and bull but it had no effect on sperm survival in any of the 3 species. Seminal plasma stimulated motility markedly in ram initially, but in all 3 species seminal plasma was detrimental to survival: in ram even a 15-min exposure to the fluid reduced survival. Serum albumin also stimulated motility; it delayed, but did not prevent, the detrimental effect of seminal plasma, although it had no effect itself on survival.

The effects of epididymal plasma, seminal plasma and serum albumin on surface properties of epididymal spermatozoa, i.e. agglutination, sticking-to-glass and eosinophilia, were also noted. These varied between species and there was no correlation between these effects and the effects on motility and survival.

\section{Introduction}

Various authors have implied that seminal plasma constitutes a beneficial environment for spermatozoa (see Mann, 1964, pp. 65-66); this view is supported by the observation that ejaculated spermatozoa die if the concentration of seminal plasma in their environment is reduced by dilution or washing (e.g. Emmens \& Swyer, 1948; Blackshaw, 1953; White, 1953; Dott \& Walton, 1960). On the other hand, a number of studies (especially on bull spermatozoa) have shown that seminal plasma can exert a direct toxic effect on epididymal spermatozoa (Shannon, 1965; Bennett \& Dott, 1966; Dott, 1974). Such a toxic effect could influence greatly the subsequent behaviour of the spermatozoa in experiments in vitro, for example after washing, and a false impression of the effect of treatments might thereby be gained.

In this series of experiments we have studied the effect on their motility and surface properties of exposing epididymal spermatozoa to seminal plasma (a) over a prolonged period and (b) for a short time.

\section{Materials and Methods}

Epididymal semen was obtained by retrograde extrusion of the luminal contents of the cauda epididymidis of bulls, rams and rabbits after slaughter (based on Lasley \& Bogart, 1944); an 
air bubble was forced along the vas deferens into the epididymal tubule under pressure by fluid from a peristaltic pump ( $\ngtr 18 \mathrm{lbf} / \mathrm{in}^{2}$, i.e. $1.2 \times 10^{5} \mathrm{~Pa}$, for bull and $\mathrm{ram} ; \ngtr 6 \mathrm{lbf} / \mathrm{in}^{2}$, i.e. $0.4 \times 10^{5} \mathrm{~Pa}$, for rabbit) and the epididymal semen was collected from the cut end of the tubule near the proximal end of the cauda. In this way, the material was subject to minimum contamination by exudate from damaged tissue and had not been diluted with any artificial medium before the start of the experiment itself.

Altogether 3 Friesian bulls, 3 Suffolk rams and 6 rabbits (from a commercial breeder) were used. An individual epididymis from each bull and ram provided enough material for the 16 treatments which constituted one experiment, whereas both epididymides from a rabbit were required. The experiment was repeated 6 times on each species.

Three different seminal plasma samples were used freshly prepared for each species, the experiment being performed on two samples of epididymal semen at a time. Seminal plasma was obtained from ejaculated semen from males of the appropriate species held at the Animal Research Station. The ejaculated semen, collected by artificial vagina, was centrifuged at $2000 \mathrm{~g}$ for $15 \mathrm{~min}$ and the supernatant was clarified by further centrifugation at $38000 \mathrm{~g}$ for $20 \mathrm{~min}$.

For each species, 4 media were involved. Medium $\mathrm{H}$ was the basal artificial medium and contained $20 \mathrm{~mm}-N$-2-hydroxyethylpiperazine- $N^{\prime}$-2-ethanesulphonic acid (HEPES: Hopkin \& Williams, Chadwell Heath, Essex), $10 \mathrm{~mm}$-glucose, $2 \mathrm{~mm}-\mathrm{Na}_{2} \mathrm{HPO}_{4}, 4 \mathrm{~mm}-\mathrm{MgCl}_{2}, 2.5 \mathrm{~mm}$ $\mathrm{KOH}, 134 \mathrm{~mm}-\mathrm{NaCl}, 7.5 \mathrm{~mm}-\mathrm{NaOH}$ and $100 \mu \mathrm{g} \mathrm{kanamycin} / \mathrm{ml}$; its osmolarity was 305 mosmol $/ \mathrm{kg}$ and its $\mathrm{pH}$ was 7.55 at $20^{\circ} \mathrm{C}\left(7.4\right.$ at $\left.30^{\circ} \mathrm{C}\right)$. Medium A consisted of Medium $\mathrm{H}$ plus $4 \mathrm{mg}$ bovine serum albumin (Sigma preparation A 4378)/ml. Medium S was homologous seminal plasma $(3.0 \mathrm{ml})$ diluted in Medium $\mathrm{H}(7.0 \mathrm{ml})$. Medium SA was homologous seminal plasma diluted similarly with Medium A.

\section{Experimental procedure}

The experiment was designed so that samples of spermatozoa should be incubated finally in various concentrations of epididymal plasma or seminal plasma, sometimes after an initial brief exposure to seminal plasma. To achieve this objective, four main treatments were used: I, simple dilution; II, washing followed by dilution in the fluid from which spermatozoa had been washed; III, washing followed by dilution in fresh Medium $\mathrm{H}$ or Medium A; IV, washing followed by dilution in $30 \%(\mathrm{v} / \mathrm{v})$ seminal plasma. These treatments were carried out using each of the four media (Medium H, A, S or SA) as the initial diluent of the epididymal semen, to yield a total of 16 treatments which we have codified on a basis of main treatment and initial diluent (see Table 1).

The epididymal semen was divided into 4 parts each of which was diluted 10-fold with one of the 4 media to give a sperm density of $3-7 \times 10^{8}$ cells $/ \mathrm{ml}$. Samples were removed from each of these and further diluted in $1.0 \mathrm{ml}$ of the same medium so that the sperm density was $1-2 \times 10^{7}$ cells $/ \mathrm{ml}$; these constituted the 4 diluted samples. After $15 \mathrm{~min}$ at room temperature the rest of the spermatozoa were removed from the medium in which they had been suspended and washed by the method described by Harrison (1976). For those spermatozoa suspended in Medium $\mathrm{H}$ or Medium S, the $7.5 \%(w / v)$ Ficoll wash medium was made up in Medium $\mathrm{H}$ while for those suspended in Medium A or Medium SA, it was made up in Medium A.

After the washing procedure, a sample of the fluid in which the spermatozoa had been suspended (the top layer in the centrifuge tube) was taken for later use; then the Ficoll medium was removed, to leave a volume such that when the spermatozoa were gently resuspended the sperm density was approximately $7 \times 10^{8}$ cells $/ \mathrm{ml}$. Finally, $20 \mu \mathrm{lsamples}$ of the four washed sperm suspensions were diluted in $1.0 \mathrm{ml}$ volumes of Medium $\mathrm{H}$, Medium $\mathrm{S}$ or the fluid from which they had been washed (Medium A, Medium SA etc. in those sets involving serum albumin), so that the final sperm density was $1-2 \times 10^{7}$ cells $/ \mathrm{ml}$. 
Table 1. Experimental treatments

\begin{tabular}{|c|c|c|c|c|}
\hline $\begin{array}{l}\text { Treatment } \\
\text { code }\end{array}$ & $\begin{array}{c}\text { Pre-wash } \\
\text { medium }\end{array}$ & $\begin{array}{l}\text { Resuspension } \\
\text { medium }\end{array}$ & $\begin{array}{l}\text { Conc.* of epididymal }(E) \\
\text { or seminal (S) plasma in } \\
\text { the final incubation } \\
\text { medium }(\%, v / v)\end{array}$ & $\begin{array}{l}\text { Effect of } \\
\text { treatment }\end{array}$ \\
\hline IH & Medium H & No washing & \multirow{2}{*}{$\begin{array}{l}\mathrm{E}=0.3 \text { (bull) } \\
\mathrm{E}=0.5 \text { (rabbit) } \\
\mathrm{E}=0.2(\text { ram })\end{array}$} & \multirow{2}{*}{$\begin{array}{l}\text { Unwashed spermatozoa } \\
\text { incubated in dilute } \\
\text { epididymal plasma }\end{array}$} \\
\hline IA & Medium A & No washing & & \\
\hline IIH & Medium $\mathbf{H}$ & $\begin{array}{l}\text { Fluid from which } \\
\text { the spermatozoa } \\
\text { had been washed }\end{array}$ & \multirow{2}{*}{$E=10$} & \multirow[t]{2}{*}{$\begin{array}{l}\text { Washed spermatozoa } \\
\text { incubated in } 10 \% \\
\text { epididymal plasma }\end{array}$} \\
\hline IIA & Medium A & $\begin{array}{l}\text { Fluid from which } \\
\text { the spermatozoa } \\
\text { had been washed }\end{array}$ & & \\
\hline IIIH & Medium H & Medium $\mathbf{H}$ & \multirow{2}{*}{$E=0.005$} & \multirow{2}{*}{$\begin{array}{l}\text { Washed spermatozoa } \\
\text { incubated in a medium } \\
\text { virtually free of } \\
\text { epididymal plasma }\end{array}$} \\
\hline IIIA & Medium A & Medium A & & \\
\hline IVH & Medium $\mathbf{H}$ & Medium S & \multirow{2}{*}{$S=30$} & \multirow{2}{*}{$\begin{array}{l}\text { Washed spermatozoa } \\
\text { incubated in } 30 \% \\
\text { seminal plasma }\end{array}$} \\
\hline IVA & Medium A & Medium SA & & \\
\hline IS & Medium S & No washing & \multirow{2}{*}{$\mathrm{S} \dagger=30$} & \multirow{2}{*}{$\begin{array}{l}\text { Unwashed spermatozoa } \\
\text { incubated in } 30 \% \\
\text { seminal plasma }\end{array}$} \\
\hline ISA & Medium SA & No washing & & \\
\hline IIS & Medium S & $\begin{array}{l}\text { Fluid from which } \\
\text { the spermatozoa } \\
\text { had been washed }\end{array}$ & \multirow{2}{*}{$\begin{array}{l}S=30 \\
E=10\end{array}$} & \multirow{2}{*}{$\begin{array}{l}\text { Washed spermatozoa } \\
\text { incubated in } 30 \% \\
\text { seminal plasma } \\
\text { supplemented by } 10 \% \\
\text { epididymal plasma }\end{array}$} \\
\hline IISA & Medium SA & $\begin{array}{l}\text { Fluid from which } \\
\text { the spermatozoa } \\
\text { had been washed }\end{array}$ & & \\
\hline IIIS & Medium S & Medium $\mathrm{H}$ & \multirow{2}{*}{$S=0.015$} & \multirow{2}{*}{$\begin{array}{l}\text { Washed spermatozoa } \\
\text { exposed briefly }(15 \mathrm{~min}) \\
\text { to } 30 \% \text { seminal plasma and } \\
\text { incubated in medium } \\
\text { virtually free of } \\
\text { seminal plasma }\end{array}$} \\
\hline IIISA & Medium SA & Medium A & & \\
\hline IVS & Medium $\mathbf{S}$ & Medium $S$ & \multirow{2}{*}{$\mathrm{S}=30$} & \multirow{2}{*}{$\begin{array}{l}\text { Washed spermatozoa } \\
\text { pretreated in } 30 \% \text { seminal } \\
\text { plasma then incubated in } \\
30 \% \text { seminal plasma }\end{array}$} \\
\hline IVSA & Medium SA & Medium SA & & \\
\hline
\end{tabular}

* Concentrations have been estimated from the manipulative procedures, using the following assumptions: sperm density in epididymal semen $=3 \times 10^{9}$ (rabbit), $5 \times 10^{9}$ (bull) or $7 \times 10^{9}$ (ram) per ml; sperm density in final incubation medium $=1.5 \times 10^{7}$ per $\mathrm{ml}$ (all species); residual milieu remaining after washing $=2.5 \% \mathrm{v} / \mathrm{v}$ (Harrison, 1976). $\mathrm{E}=$ epididymal plasma as a percentage of concentration in the epididymis $(\mathrm{v} / \mathrm{v}) . \mathrm{S}=$ seminal plasma as a percentage of the concentration in artificially collected ejaculates $(\mathrm{v} / \mathrm{v})$.

$\dagger$ The presence of very small quantities of additional epididymal plasma in the final incubation medium has been ignored; large quantities of epididymal plasma are already present in seminal plasma. 


\section{Evaluation of treatments}

The final diluted sperm suspensions, of which there were 32 on each occasion, were incubated in the dark at $30^{\circ} \mathrm{C}$ in small tubes open to the air. The tubes were coded and randomized, using a different set of random numbers each time. After 1, 3, 7, 11 and $22 \mathrm{~h}$ of incubation, subsamples $(5-10 \mu \mathrm{l})$ from each tube were presented to two independent observers; assessments of motility, head-to-head association ('agglutination'), and adhesion to the surface of the glass slide ('sticking-to-glass') were carried out as described by Harrison et al. (1978). During the first hour of incubation, other subsamples from each tube were stained with nigrosin-eosin (Dott \& Foster, 1972).

\section{Analysis of results}

Because earlier experiments (Harrison et al., 1978) showed no difference between assessments by the different observers, all data for each parameter at each time were pooled for the analyses of the different treatments.

There are problems involved when data from restricted scales are analysed statistically (see Snedecor \& Cochran, 1967), therefore two methods of analysis were used to analyse the motility data, one of which did not make any assumptions regarding the linearity of the grading scale or the distribution of the observations. In one method, the motility grades were assigned numerical values which were subjected to 3-way analysis of variance, the variables being initial diluent, treatment and semen sample. The residual error was used to test the significance of variation of these treatments and 2-way interactions. This type of analysis was used for the motility assessments from each observation time; in addition a similar analysis was carried out of differences $\left(t_{0}-t_{x}\right)$ between the assigned values at $1 \mathrm{~h}\left(\mathrm{t}_{0}\right)$ and those at $3,7,11$ or $22 \mathrm{~h}\left(\mathrm{t}_{\mathrm{x}}\right)$. In the other method of analysis, frequencies of occurrence of the various grades of motility were determined and $\chi^{2}$ tests were applied to the frequency distribution to assess the significance of differences between treatments (Harrison, Dott \& Foster, 1978). The $\chi^{2}$ tests and the analyses of variance confirmed each other. The figures used in the analyses of variance have been used to illustrate the results (Text-figs 1 and 2).

Observations of the occurrence of agglutination and sticking-to-glass were analysed by a $\chi^{2}$ test (Harrison et al., 1978). The proportion of spermatozoa which were non-eosinophilic after each treatment was transformed to angles and an analysis of variance was done on the transformed values.

Any changes mentioned in the 'Results' have a probability of $<0.01$ of being due to chance.

\section{Results}

In the 960 samples from each species that were examined during this experiment, $98 \cdot 5,95 \cdot 5$ and $89.8 \%$ of those from bull, ram and rabbit respectively contained motile cells. The mean number of different grades assigned to each species at any given examination time for any one treatment was respectively $4.2,3.6$ and 3.6 out of a possible 8 (these figures give an indication of the 'experimental error'). The initial motility scores (after $1 \mathrm{~h}$ of incubation) were higher for ram spermatozoa than for bull or rabbit. The proportion of non-eosinophilic spermatozoa was very high $(>80 \%)$ in all species and very few morphologically abnormal cells were seen. There were agglutinated spermatozoa in $71 \%$ of ram samples, $41 \%$ of bull and $37 \%$ of rabbit, and spermatozoa were observed sticking-to-glass less frequently in bull samples $(50 \%)$ than in ram and rabbit samples ( $57 \%$ and $58 \%$ respectively).

The motility scores and the frequency of occurrence of agglutination and sticking-to-glass varied depending on the initial diluent and the subsequent treatment. Analysis of variance of the motility scores showed that the samples from different bulls varied in their response to the diluents whereas the samples from ram and rabbit did not vary in this way; nevertheless, the 
variability between bull samples did not affect the validity of our findings on the effect of the treatments.

\section{Effect of pH changes on motility}

The $\mathrm{pH}$ of all the ram samples was measured after $22 \mathrm{~h}$ of incubation. The $\mathrm{pH}$ in Medium $\mathrm{H}$ and Medium A, in which the spermatozoa survived best (see below), was found to be $7.09 \pm$ 0.02 ; thus the level of buffering power in the system was quite sufficient to maintain an adequate $\mathrm{pH}$ over the duration of our experiments. The $\mathrm{pH}$ of the subsamples varied but this variation was not related to motility. Measurements of $\mathrm{pH}$ were not carried out on bull and rabbit samples because the metabolism of these spermatozoa would not have overtaxed the buffering capacity of the system if ram spermatozoa did not (compare metabolic rates given by Mann, 1964).

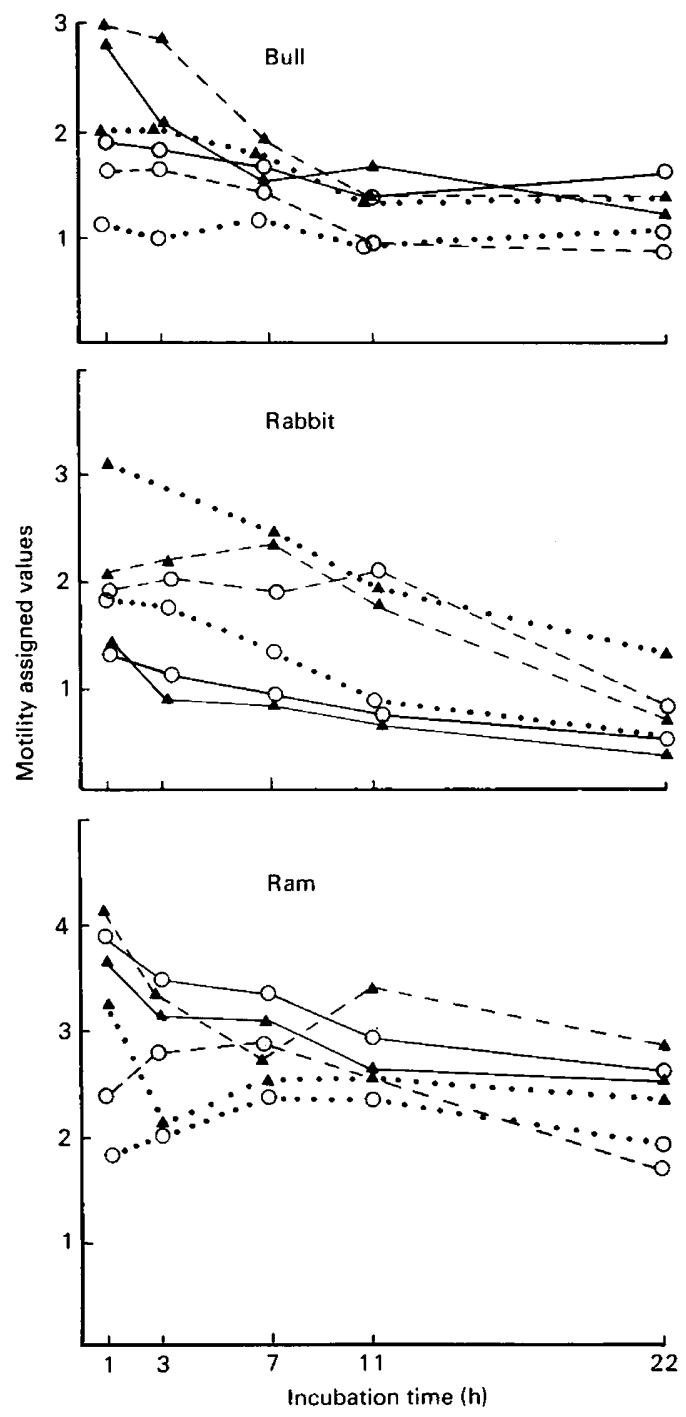

Text-fig. 1. Motility of epididymal spermatozoa when incubated in Medium $\mathrm{H}(\mathrm{O})$ or Medium A (৯) containing different concentrations of epididymal plasma: $\cdots, \cdots, 0.005 \%$ (Treatment III); ,$--- 0.3 \%$ (bull), $0.5 \%$ (rabbit), or $0.2 \%$ (ram) (Treatment I); $\longrightarrow, 10 \%$ (Treatment II). 


\section{Effect of washing procedure}

It has been maintained that washing per se is detrimental to spermatozoa (e.g. Dott \& Walton, 1960; Jones \& Holt, 1974). The interpolation of a washing step in many of our treatments might have influenced the subsequent behaviour of spermatozoa. However, from Table 1 it can be seen that the concentration of seminal plasma in the final incubation medium was the same in the Treatments IS and IVS and in their albumin-containing equivalents (ISA and IVSA). The difference between Treatments I and IV was that in IV the spermatozoa had been washed whereas in I they had simply been diluted. There were no differences in any of the parameters in any of the species between these two main treatments; the actual values were similar to those shown for Treatments IVH and IVA in Text-fig. 2 and Table 2 but as they are of no intrinsic
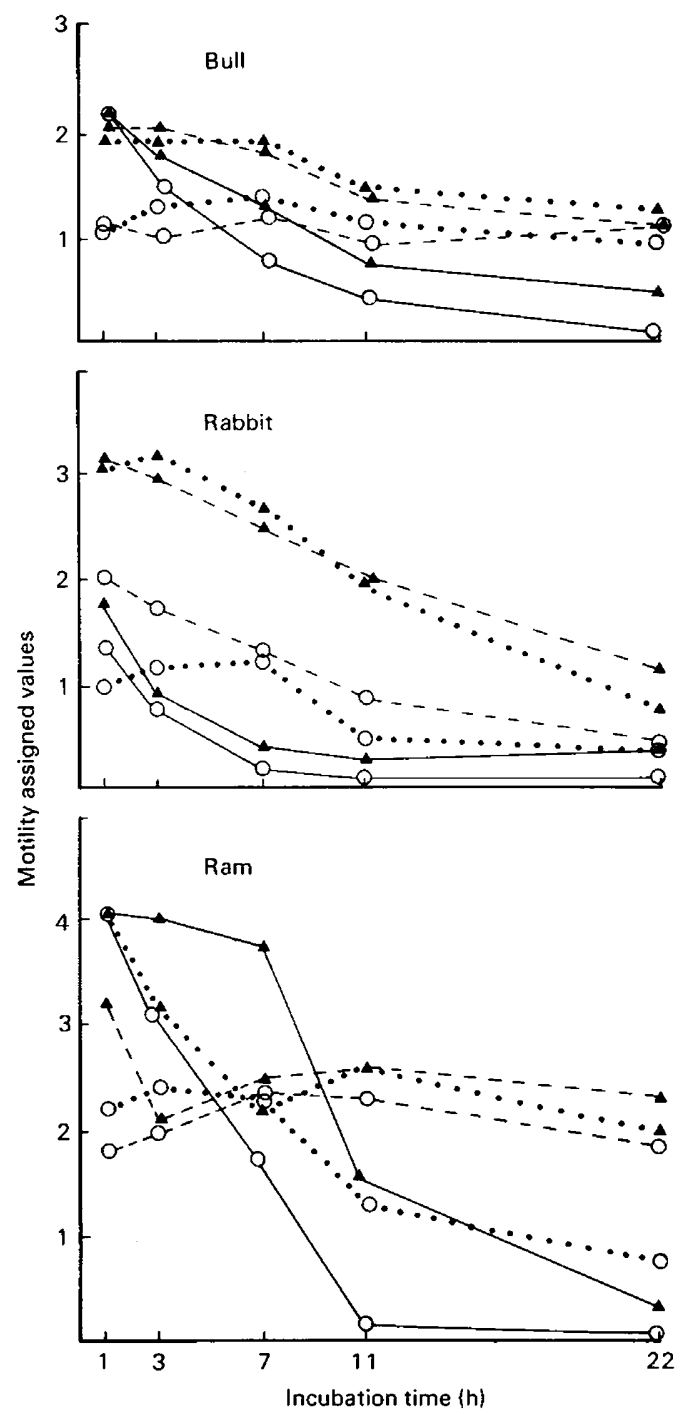

Text-fig. 2. Motility of washed epididymal spermatozoa when incubated in Medium $S$ (Treatment IVS, $\mathrm{O} \longrightarrow \mathrm{O}$ ) or Medium SA (Treatment IVSA, $\Delta-\Delta$ ), Medium H (Treatment IIIH, O-- - O) or Medium A (Treatment IIIA, $\mathbf{A - - \Delta}$ ), or in Medium H (Treatment IIIS, $0 \cdots$ ) or Medium A (Treatment IIISA, $\Delta \cdots . \cdots$ ) after $15 \mathrm{~min}$ exposure to $30 \%$ seminal plasma. 
Table 2. Effect of epididymal plasma on surface properties of epididymal spermatozoa: percentage of samples with agglutinated spermatozoa (AGG), percentage of samples with spermatozoa sticking-to-glass (STG) and mean percentage of non-eosinophilic spermatozoa (NON-EOS)

\begin{tabular}{|c|c|c|c|c|c|c|c|c|c|}
\hline \multirow{2}{*}{ Epididymal plasma conc. } & \multicolumn{3}{|c|}{ No albumin } & \multicolumn{3}{|c|}{ Albumin present } & \multicolumn{3}{|c|}{$\begin{array}{l}\text { Probable significance of difference } \\
\text { due to albumin }\end{array}$} \\
\hline & AGG & STG & NON-EOS & AGG & STG & NON-EOS & AGG & STG & NON-EOS \\
\hline \multicolumn{10}{|l|}{ Bull } \\
\hline $0.005 \%(\mathrm{IIIH}, \mathrm{IIIA})$ & 83 & 97 & 81 & 87 & 82 & 83 & & & \\
\hline $0 \cdot 3 \%(1 \mathrm{H}, \mathrm{IA})$ & 57 & 92 & 88 & 67 & 45 & 92 & & $<0.001$ & \\
\hline $10 \%(\mathrm{IIH}$, IIÁ) & 19 & 14 & 90 & 23 & 25 & 84 & & & \\
\hline \multicolumn{10}{|l|}{$\begin{array}{l}\text { Probable significance } \\
\text { of difference }\end{array}$} \\
\hline III versus II & $<0.001$ & $<0.001$ & & $<0.001$ & $<0.001$ & & & & \\
\hline I versus II & $<0.001$ & $<0.001$ & & $<0.001$ & & & & & \\
\hline \multicolumn{10}{|l|}{ Rabbit } \\
\hline $0.005 \%$ (IIIH, IIIA) & 56 & 95 & 61 & 57 & 58 & 86 & & $<0.001$ & $<0.001$ \\
\hline $0.5 \%(\mathrm{IH}, \mathrm{IA})$ & 37 & 90 & 56 & 40 & 57 & 86 & & $<0.001$ & $<0.001$ \\
\hline $10 \%$ (IIH, IIÁ) & 26 & 48 & 86 & 21 & 45 & 88 & & & \\
\hline \multicolumn{10}{|l|}{$\begin{array}{l}\text { Probable significance } \\
\text { of difference }\end{array}$} \\
\hline III versus II & $<0.001$ & $<0.001$ & $<0.001$ & $<0.001$ & & & & & \\
\hline I versus II & & $<0.001$ & $<0.001$ & & & & & & \\
\hline \multicolumn{10}{|l|}{ Ram } \\
\hline $0.005 \%(\mathrm{IIIH}$, IIIA) & 52 & 95 & 71 & 22 & 95 & 78 & $<0.001$ & & \\
\hline $0.2 \%(\mathrm{IH}, \mathrm{IA})$ & 63 & 90 & 80 & 100 & 85 & 88 & $<0.001$ & & \\
\hline $10 \%($ IIH, IIA $)$ & 83 & 39 & 80 & 92 & 28 & 80 & & & \\
\hline \multicolumn{10}{|l|}{$\begin{array}{l}\text { Probable significance } \\
\text { of difference }\end{array}$} \\
\hline III versus I & & & & $<0.001$ & & & & & \\
\hline III versus II & $<0.001$ & $<0.001$ & & & $<0.001$ & & & & \\
\hline I versus Ii & & $<0.001$ & & & $<0.001$ & & & & \\
\hline
\end{tabular}

interest they are not presented. It was concluded that the washing procedure itself had no effect upon the response of the spermatozoa to the various incubation media. Further evidence supporting this conclusion was obtained from the effects of epididymal plasma (see below).

\section{Effect of epididymal plasma}

Survival of spermatozoa within the cauda epididymidis is protracted (see Orgebin-Crist, Danzo \& Cooper, 1976), and epididymal plasma has been reported to prolong the survival of hamster spermatozoa in vitro (Morton \& Chang, 1973). The effect of different concentrations of epididymal plasma on bull, rabbit and ram spermatozoa can be observed by comparing Treatments IH, IIH and IIIH, and also their albumin-containing equivalents, Treatments IA, IIA and IIIA (see Text-fig. 1 and Table 2).

In the absence of serum albumin, increasing concentrations of epididymal plasma resulted in slightly higher levels of sperm motility in bull and ram. In rabbit, however, motilities were lowest in the highest concentration of epididymal plasma. In the presence of serum albumin, motilities were almost invariably higher and there was little correlation of motility level with concentration of epididymal plasma, although the detrimental nature of rabbit epididymal plasma was confirmed. There was no evidence that epididymal plasma prolonged sperm survival in any of the species in terms of maintaining motility levels; although there were differences in motility levels, the particular levels were maintained to the same degree whatever the concentration of epididymal plasma present. Survival in the simple saline-based Medium H (residual epididymal plasma $<0.005 \% \mathrm{v} / \mathrm{v}$ ) was very good, there being little decline in sperm motility over $22 \mathrm{~h}$ in bull and ram, and only a moderate decline in rabbit. 
The surface properties of the spermatozoa responded differently to epididymal plasma depending upon the species. In bull and rabbit, agglutination and sticking-to-glass decreased as the concentration of epididymal plasma was increased; in ram, sticking-to-glass followed the same pattern whereas agglutination increased as the epididymal plasma concentration was increased. Albumin did not modify these effects to any great extent in bull and ram, but in rabbit albumin itself reduced sticking-to-glass and an additional effect of epididymal plasma was then not seen. The proportion of non-eosinophilic bull and ram spermatozoa was unaffected either by epididymal plasma or by albumin; however, in rabbit there were more non-eosinophilic cells in high concentrations of epididymal plasma or in the presence of albumin.

The intermediate concentration of epididymal plasma occurred in samples which had been diluted but not washed, and the intermediate effects produced are additional evidence of the minimal consequences of washing. Elsewhere in this paper levels of reproductive tract fluids in the incubation media are expressed as a percentage $(\mathrm{v} / \mathrm{v})$ of the concentration encountered in vivo. Whereas on this basis the levels of epididymal plasma in our treatments ranged from 0.005 to $10 \%$, the levels ranged from 1 to $45000 \%$ of that encountered in vivo when expressed on the basis of plasma per spermatozoon.

\section{Effect of continuous exposure to seminal plasma}

The effect of seminal plasma on washed spermatozoa was elicited by comparing Treatments IVH with IIIH, and IVA with IIIA (Text-fig. 2 and Table 3). Initially the motility of bull and ram

Table 3. Effect of seminal plasma on surface properties of epididymal spermatozoa: percentage of samples with agglutinated spermatozoa (AGG), percentage of samples with spermatozoa sticking to glass (STG) and mean percentage of non-eosinophilic spermatozoa (NON-EOS)

\begin{tabular}{|c|c|c|c|c|c|c|c|c|c|}
\hline \multirow{2}{*}{$\begin{array}{l}\text { Seminal plasma } \\
\text { (Treatment) }\end{array}$} & \multicolumn{3}{|c|}{ No albumin } & \multicolumn{3}{|c|}{ Albumin present } & \multicolumn{3}{|c|}{$\begin{array}{l}\text { Probable significance of difference } \\
\text { due to albumin }\end{array}$} \\
\hline & $\mathrm{AGG}$ & STG & NON-EOS & AGG & STG & NON-EOS & $\mathrm{AGG}$ & STG & NON-EOS \\
\hline \multicolumn{10}{|l|}{ Bull } \\
\hline None (IIIH, IIIA) & 83 & 97 & 81 & 87 & 82 & 83 & & & \\
\hline \multicolumn{10}{|l|}{ Brief exposure } \\
\hline (IIIS, IIISA) & 81 & 93 & 83 & 83 & 72 & 86 & & $<0.001$ & \\
\hline $30 \%$ (IVH, IVHA) & 21 & 15 & 82 & 20 & 14 & 84 & & & \\
\hline \multicolumn{10}{|l|}{$\begin{array}{l}\text { Probable significance } \\
\text { of difference }\end{array}$} \\
\hline IIIH versus IVH & $<0.001$ & $<0.001$ & & $<0.001$ & $<0.001$ & & & & \\
\hline IIIS versus IVH & $<0.001$ & $<0.001$ & & $<0.001$ & $<0.001$ & & & & \\
\hline \multicolumn{10}{|l|}{ Rabbit } \\
\hline None (IIIH, IHIA) & 56 & 95 & 61 & 57 & 58 & 86 & & $<0.001$ & $<0.001$ \\
\hline \multicolumn{10}{|l|}{ Brief exposure } \\
\hline (IIIS, IIISA) & 30 & 77 & 54 & 53 & 55 & 86 & $<0.001$ & $<0.001$ & $<0.001$ \\
\hline $30 \%$ (IVH, IVA) & 35 & 29 & 87 & 37 & 48 & 88 & & & \\
\hline \multicolumn{10}{|l|}{$\begin{array}{l}\text { Probable significance } \\
\text { of difference }\end{array}$} \\
\hline IIIH versus IIIS & $<0.001$ & & & & & & & & \\
\hline IIIH versus IVH & $<0.001$ & $<0.001$ & $<0.001$ & & & & & & \\
\hline IIIS versus IVH & & $<0.001$ & $<0.001$ & & & & & & \\
\hline \multicolumn{10}{|l|}{ Ram } \\
\hline None (IIIH, IIIA) & 52 & 95 & 71 & 22 & 95 & 78 & $<0.001$ & & \\
\hline \multicolumn{10}{|l|}{ Brief exposure } \\
\hline (IIIS, IIISA) & 98 & 91 & 67 & 100 & 93 & 86 & & & \\
\hline $30 \%$ (IVH, IVA) & 63 & 28 & 82 & 68 & 20 & 89 & & & \\
\hline \multicolumn{10}{|l|}{$\begin{array}{l}\text { Probable significance } \\
\text { of difference }\end{array}$} \\
\hline IIIH versus IIIS & $<0.001$ & & & $<0.001$ & & & & & \\
\hline IIIH versus IVH & & $<0.001$ & & $<0.001$ & $<0.001$ & & & & \\
\hline IIIS versus IVH & $<0.001$ & $<0.001$ & & $<0.001$ & $<0.001$ & & & & \\
\hline
\end{tabular}


spermatozoa was enhanced, particularly so in ram. However, the enhancement was short lived, for by $3 \mathrm{~h}$ motility levels had already declined and by $11 \mathrm{~h}$ they were very low. The presence of albumin had no effect upon the initial motility levels observed in seminal plasma but it did, in ram particularly, delay (and reduce somewhat) the decline in motility. In rabbit this decline was very rapid and no separate stimulatory effect was observed; albumin reduced the decline slightly, as in the other species.

Seminal plasma reduced sticking-to-glass in all three species and reduced agglutination in bull. Albumin did not modify these effects in bull, but of itself it reduced sticking-to-glass in rabbit and the seminal plasma effect on this parameter was then not seen. In ram, seminal plasma reversed an effect of albumin on agglutination. The proportion of non-eosinophilic spermatozoa in bull and ram ( 82.5 and $80 \%$ respectively) was unaffected by seminal plasma and/or albumin. But in rabbit the proportion of non-eosinophilic spermatozoa was higher in the presence of either seminal plasma or albumin (61 to $87 \%$ ).

Comparison of other treatments could be used to demonstrate the effect of seminal plasma on spermatozoa, for example Treatment IS versus IH, and ISA versus IA. The results of these comparisons were indistinguishable from those presented. The prior exposure of spermatozoa to seminal plasma before washing had no effect upon the response of these spermatozoa to seminal plasma in the final incubation medium (Treatments IVS versus IVH, and IVSA versus IVA); similarly, neither the presence of increased levels of epididymal plasma (e.g. Treatments IIS versus IVS, and IISA versus IVSA) nor the interpolation of a washing step (Treatments IVS versus IS, and IVSA versus ISA) modified the response to seminal plasma.

\section{Effect of a brief exposure to seminal plasma}

A brief exposure to seminal plasma (Treatments IIIS and IIISA) did appear to modify the response of spermatozoa to Medium $\mathrm{H}$ and Medium $\mathrm{A}$. The concentration of seminal plasma in the final incubation medium after these treatments was $0.015 \%$ (Table 1). In other experiments (unpublished) we have shown that incubation in concentrations of seminal plasma as low as this has no effect on the parameters being studied. therefore any effect produced (Treatments IIIS versus IIIH, and IIISA versus IIIa) can be attributed to prior exposure of the spermatozoa to $30 \%$ seminal plasma for 15 min (see Text-fig. 2 and Table 3 ).

The motility of bull and rabbit spermatozoa was unaffected by their brief exposure, in the presence or absence of albumin (there was some evidence for lower motility levels in rabbit in the absence of albumin but this was not significant). In ram spermatozoa in Medium $\mathrm{H}$, there was clearly a decline in motility in those spermatozoa that had been pretreated with seminal plasma, although in the presence of albumin (Medium A) the decline was not apparent. The stimulation of motility by seminal plasma was observed after brief exposure only if albumin was present, and this stimulation was relatively short-lived.

Brief exposure to seminal plasma greatly increased the agglutination of ram spermatozoa in Medium $\mathrm{H}$ and Medium A, but no other effects on surface properties were observed in any of the three species.

\section{Effect of serum albumin}

Serum albumin increased levels of motility in all three species although its effect was modified by the reproductive tract fluids (see Text-figs 1 and 2, and Tables 2 and 3). Albumin had little or no effect upon the maintenance or decline in motility levels in the absence of reproductive tract fluids, but in most cases was able to modify any decline caused by these fluids (see results described above). In rabbit, albumin reduced sticking-to-glass and increased the proportion of non-eosinophilic spermatozoa, whereas in ram it reduced agglutination. It had no effect on the surface properties of bull spermatozoa except that it reduced sticking-to-glass of spermatozoa 
that had been pretreated with seminal plasma or that were in the presence of dilute epididymal plasma (Treatment IA).

\section{Discussion}

The environment encountered by the spermatozoa in our experiments was in some cases equivalent to that resulting from a dilution of epididymal semen to 1:20000 (Treatments IIIH and IIIA) or a dilution of ejaculated semen to 1:6000 (Treatments IIIS and IIISA). It has been reported that dilution rates of this magnitude severely impair motility and survival (see Mann, 1964, pp. 343-352). That motility and survival were not obviously impaired in our treatments implies that the presence of appreciable levels of male reproductive tract fluids in the sperm environment is not of primary importance for sperm function. On the other hand, in our experiments the spermatozoa were incubated at concentrations equivalent to a dilution of epididymal semen to only $1: 200-1: 500$, or of ejaculated semen to $1: 10-1: 200$. Assessment of the motility of spermatozoa at very high dilutions (such as $1: 6000$ or $1: 20000$ ) poses problems: nevertheless, observations of spermatozoa swimming away from a group into a cell-free area suggest that the solitary spermatozoon is not viable (H. M. Dott, unpublished; see also Nevo \& Mohan, 1968). It therefore seems possible that there is some cell-associated factor essential to sperm function which passes into and out of spermatozoa, and that proximity of cells is necessary for the provision of adequate levels of this factor. Other authors have already reported the existence of such a factor (Bavister, 1974; Hanada \& Chang, 1976; Bavister \& Yanagimachi, 1977), but its connection with a 'dilution effect' has not been proposed in precisely this fashion before.

The behaviour of sperm populations in our media (Text-fig. 2) shows clearly that initial levels of motility were independent of capabilities for maintaining those levels. It is most important to distinguish between the actual degree of motility exhibited at any one time (which may perhaps reflect the presence or absence of a hormone-type motility-stimulating factor-see above) and capability of maintaining motility for long periods of time (which may reflect a degree of

Table 4. Motility of washed ejaculated spermatozoa (data for 1,3 and $5 \mathrm{~h}$ incubations from Harrison et al., 1978) and epididymal spermatozoa (data for 1,3 , and $7 \mathrm{~h}$ incubations from Treatments IIIS and IIISA) washed after brief exposure to seminal plasma

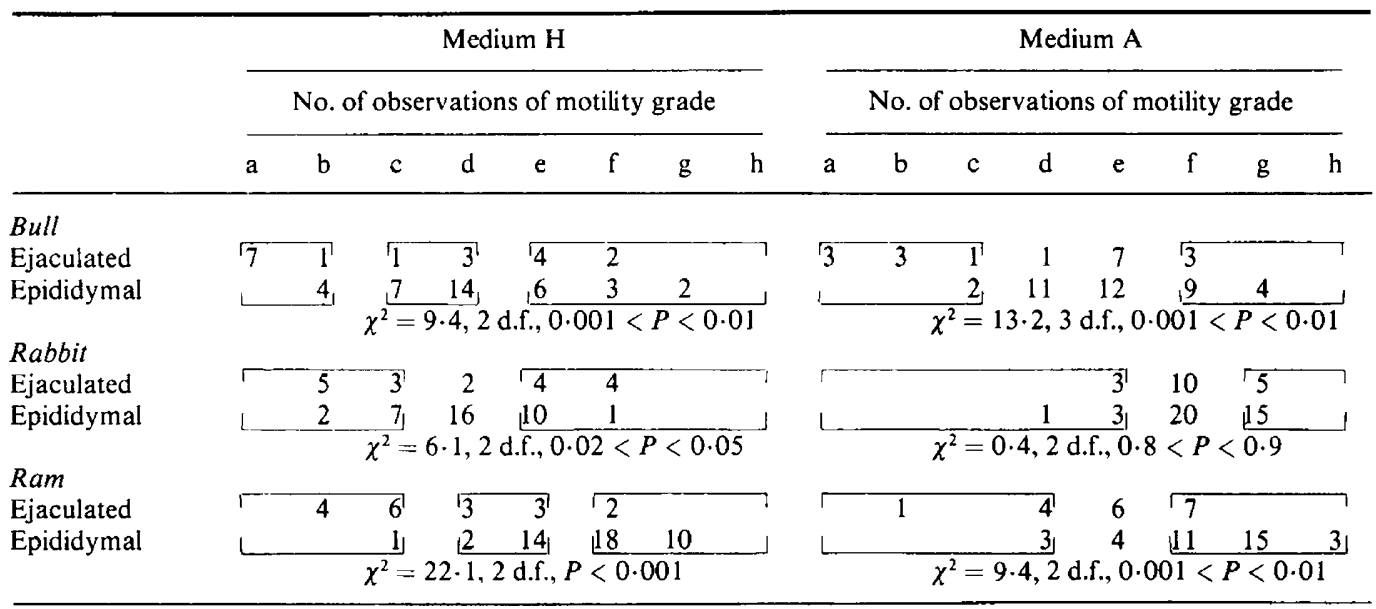

The distribution of motility grades was analysed as a contingency table in the expectation that the distribution would be the same in epididymal and ejaculated samples. The $\chi^{2}$ indicates the probability that the distribution was the same. To satisfy statistical requirements, figures in each row of the bracketed columns were summed before analysis. 
membrane stability within the population). One can conclude from the results presented in this paper that there is a motility-stimulating factor in ram seminal plasma at least, but that seminal plasma is at the same time detrimental to survival; on the other hand, rabbit epididymal plasma reduced motility but did not affect survival. The present results also show that the beneficial effect of serum albumin on spermatozoa noted by us and by others (see Harrison et al., 1978) is apparently mediated through a motility-stimulating effect and not through any effect on survival, although albumin seemed to delay the detrimental effect of seminal plasma.

The independence of motility level and sperm survival is mirrored by the equal independence of sperm surface properties and survival. Agglutination, sticking-to-glass and eosinophilia are not apparently connected in any way with each other, nor do they seem to relate to a state of integrity. For example, others have implied that dead spermatozoa stick to glass (Bangham \& Hancock, 1955; McGrath, Hillman \& Nadijcka, 1977), yet seminal plasma always reduced sticking-to-glass in all three sperm species we studied. Such surface properties are, however, an indication of the state of the cell surface and we believe them to be important indicators of sperm function.

In most, if not all, species the contributions of the various parts of the male reproductive tract to the ejaculate are voided in sequence. There is no reason to suppose that these contributions are thoroughly mixed together in vivo; thus spermatozoa in an artificially collected ejaculate (from an artificial vagina, electroejaculation or recovered from the female tract post coitum) may have been exposed to conditions which they would not normally encounter. Moreover, it is possible that in the female the 'fertilizing' spermatozoa penetrate the cervical canal or insert themselves into crypts in the uterus, thus moving out of contact with seminal plasma unmodified by fluid from the female tract, far more rapidly than spermatozoa can usually be isolated from the seminal plasma of an artificially collected ejaculate. In our present experiments, even spermatozoa that had only been exposed to $30 \%$ seminal plasma for 15 min did not in all cases behave like those spermatozoa that had never been exposed to it. The effect of longer exposure to undiluted seminal plasma is illustrated in Table 4. Clearly, the distribution of motility grades differ between ejaculated and 'exposed' epididymal cells, at least in bull and ram. We conclude that the basic parameters of sperm function can be studied more reliably if mature cells from the cauda epididymidis are used.

\section{References}

Bangham, A.D. \& Hancock, J.L. (1955) A new method for counting live and dead bull spermatozoa. Nature, Lond. 176, 656 .

Bavister, B.D. (1974) The effect of variations in culture conditions on the motility of hamster spermatozoa. $J$. Reprod. Fert. 38, 431-440.

Bavister, B.D. \& Yanagimachi, R. (1977) The effects of sperm extracts and energy sounds on the motility and acrosome reaction of hamster spermatozoa in vitro. Biol. Reprod. 16, 228-237.

Blackshaw, A.W. (1953) The motility of ram and bull spermatozoa in dilute suspension. J. gen. Physiol. 36. $449-462$.

Bennett, J.P. \& Dott, H.M. (1966) An effect of bovine seminal plasma on the impedance change frequency of epididymal spermatozoa collected from the living bull. J. Reprod. Fert. 12, 327-336.

Dott, H.M. (1974) The effects of bovine seminal plasma on the impedance change frequency and glycolysis of bovine epididymal spermatozoa. J. Reprod. Fert. 38. $147-156$.
Dott, H.M. \& Foster, G.C. (1972) A technique for studying the morphology of mammalian spermatozoa which are eosinophilic in a differential 'live/dead' stain. J. Reprod. Fert. 29, 443-445.

Dott, H.M. \& Walton, A. (1960) Effects of dilution and washing on ram spermatozoa studied by the flow dialysis technique. J. Reprod. Fert. 1, 350-367.

Emmens, C.W. \& Swyer, G.I.M. (1948) Observations on the motility of rabbit spermatozoa in dilute suspension. J. gen. Physiol. 32, 121-138.

Hanada, A. \& Chang, M.C. (1976) In vitro fertilization of hamster eggs in different medium and the stimulating effect of heterologous and homologous spermatozoa. J. Reprod. Fert. 46, 105-114.

Harrison, R.A.P. (1976) A highly efficient method for washing mammalian spermatozoa. J. Reprod. Fert. 48, $347-353$.

Harrison, R.A.P., Dott, H.M. \& Foster, G.C. (1978) Effect of ionic strength, serum albumin and other macromolecules on the maintenance of motility and the surface of mammalian spermatozoa in a simple medium. J. Reprod. Fert. 52, 65-73. 
Jones, R.C. \& Holt, W.V. (1974) The effects of washing on the ultrastructure and cytochemistry of ram spermatozoa. J. Reprod. Fert. 41, 159-167.

Lasley, J.F. \& Bogart, R. (1944) A comparative study of epididymal and ejaculated spermatozoa of the boar. J. Anim. Sci. 3, 360-370.

Mann, T. (1964) The Biochemistry of Semen and of the Male Reproductive Tract. Methuen, London.

McGrath, J., Hillman, N. \& Nadijcka, M. (1977) Separation of dead and live mouse spermatozoa. Devl Biol. 61, 114-117.

Morton, B. \& Chang, T.S.K. (1973) The effect of fluid from the cauda epididymidis, serum components and caffeine upon the survival of diluted epididymal hamster spermatozoa. J. Reprod. Fert. 35, 255-263.
Nevo, A.C. \& Mohan, R. (1969) Migration of motile sperm into sperm-free medium and the "dilution effect". J. Reprod. Fert. 18, 379-381.

Orgebin-Crist, M.C., Danzo, B.J. \& Cooper, T.G. (1976) Re-examination of the dependence of epididymal sperm viability on the epididymal environment. $J$. Reprod. Fert., Suppl. 24, $115-128$.

Shannon, P. (1965) Presence of a heat-labile toxic protein in bovine seminal plasma. J. Dairy Sci. $\mathbf{4 8}$, 1362-1365.

Snedecor, G.W. \& Cochran, W.G. (1967) Statistical Methods. The Iowa State University Press, Ames, Iowa.

White, I.G. (1953) The effect of potassium on the washing and dilution of mammalian spermatozoa. Aust.J. exp. Biol. 31, 193-200.

Received 17 May 1978 